\title{
Leiomyosarcoma with Unknown Primary
}

\author{
Manika Khare*, Ashish Airun, Umesh babu sharma and S.K. Jain \\ Dept. of Pathology, Jaipur National University, Institute Of Medical Sciences And Research Centre, Jaipur, India
}

\begin{abstract}
Leiomyosarcoma is a malignant tumor which does not arise from the leiomyoma. Leiomyosarcoma is an extremely rare form of cancer and accounts for $5-10 \%$ of soft tissue sarcomas, which are in themselves relatively rare. This case report shows unusual presentation of the multifocal leiomyosarcoma along with diagnostic dilemma. The prognosis and treatment modality are also discussed in the discussion.
\end{abstract}

Keywords: Leiomyosarcoma, Multifocal, Poor Prognosis

\section{Introduction}

Leiomyosarcoma is a malignant tumor which do not arise from the leiomyoma. ${ }^{[1]}$ Leiomyosarcoma is an extremely rare form of cancer and accounts for 5-10\% of soft tissue sarcomas, which are in themselves relatively rare. ${ }^{[2]}$ It is a resistant cancer, meaning generally not very responsive to chemotherapy or radiation. The best outcomes occur when it can be removed surgically with wide margins early, while small and still in situ. ${ }^{[3]}$

\section{Case Report}

A 32 years female presented with loose motions since 3-4 days, nausea since 1 month and bilateral foot oedema and right abdominal mass since 6 months. On general examination pallor was present along with bilateral pedal oedema and abdominal distension. Other system examination was within normal limits. Per abdomen examination showed a large palpable mass in the right hypochondriac region. There was the past history of hysterectomy 5 years back.on routine investigation patient was anemic with hemoglobin of $8.9 \mathrm{gm} / \mathrm{dl}$. Other indices and biochemical investigations were within normal limits. USG abdomen was done which showed a large 90X $85 \mathrm{~mm}$ echogenic area along inferior aspect of liver along with a large solid cystic mass in the pelvis. Multiple peritoneal deposits of various sizes were also seen. Bilateral ovaries were not identified. Based on the above findings a possibility of ovarian carcinoma was given. Further CECT abdomen was done which showed a large complex solid cystic mass in bilateral adenexa. [Fig 1] Multiple variably sized solid and cystic deposits in peritoneum, mesentery, omentum and serosal deposits on surface of small and large bowel were seen. Large hepatic sub capsular deposits causing scalloping of liver and other adjacent structures were also noted. Hence final impression of carcinoma ovary (bilateral) with abdominal deposits was given.
Endocrinology showed a raised CA125 levels $(205 \mathrm{U} / \mathrm{ml}$ normal range - up to $35 \mathrm{U} / \mathrm{ml}$ ). FNAC of the lesion was done outside, and a diagnosis of benign spindle lesion was given. Laprotomy of the patient was done and specimen was sent to histopathology laboratory. We received multiple specimens including right lobe liver mass, appendix with mass, and multiple pelvic mass, omental pieces with mass and rectal sheath mass. On gross examination all the specimens were alike with outer nodular surface. Cut surface was grey white with many cystic areas. [Fig 2] Cysts were filled with necrotic material. Multiple sections were taken for the histopathological examination which showed the similar morphology. Tumor was well encapsulated with tumor cells predominantly arranged in sheets and at places in small interlacing fascicles. Tumor cells were predominantly spindle in shape with elongated hyper chromatic nuclei and ill-defined eosinophilic cytoplasm. At places few tumor cell were small with round nucleus and clear cytoplasm, indicating the epithelioid differentiation. Occasional mitosis was seen.[Fig3, 4] Areas of necrosis were also noted. Based on the above histomorphological findings two differntials were kept - extra intestinal stromal tumor and leiomyosarcoma. Further IHC panel was applied. Tumor showed cytoplasmic positivity for vimentin and smooth muscle actin and was negative for CD 117 and CD 34, excluding the possibility of extra intestinal stromal tumor.[Fig 5] Hence final diagnosis of leimyosarcoma of unknown primary was given.

\section{Discussion}

Leiomyosarcoma is the malignant tumor of mesenchymal origin. It originates from the smooth muscle component of the soft tissue. Most common primary site for leiomyosarcoma is the retroperitonium, which accounts $50 \%$ of all cases (in this case, there was no retroperitoneal mass on imaging $)^{[4]}$. Soft-tissue leiomyosarcoma usually 


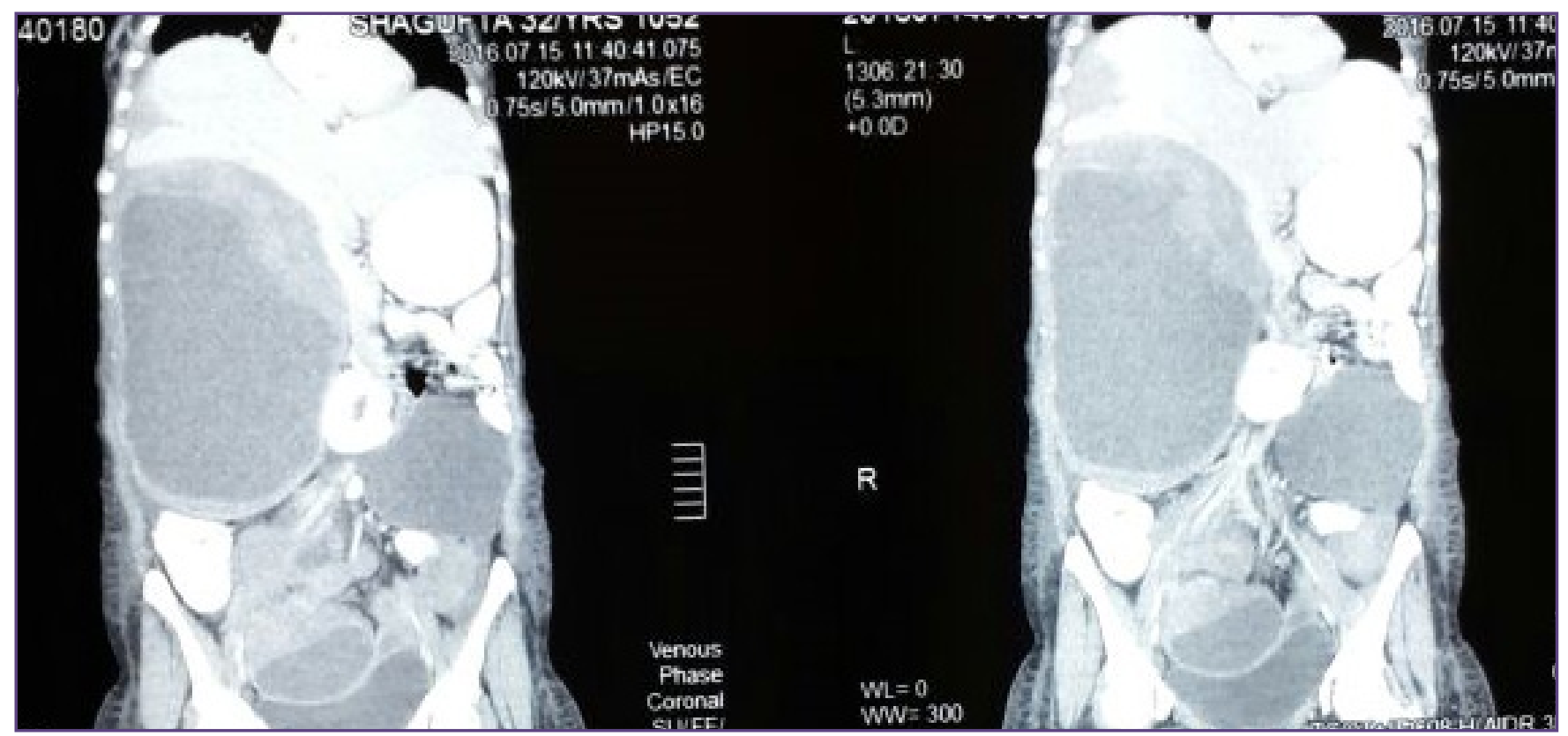

Fig. 1. Picture shows multifocal mass in the abdomen, largest seen in the abdomen.

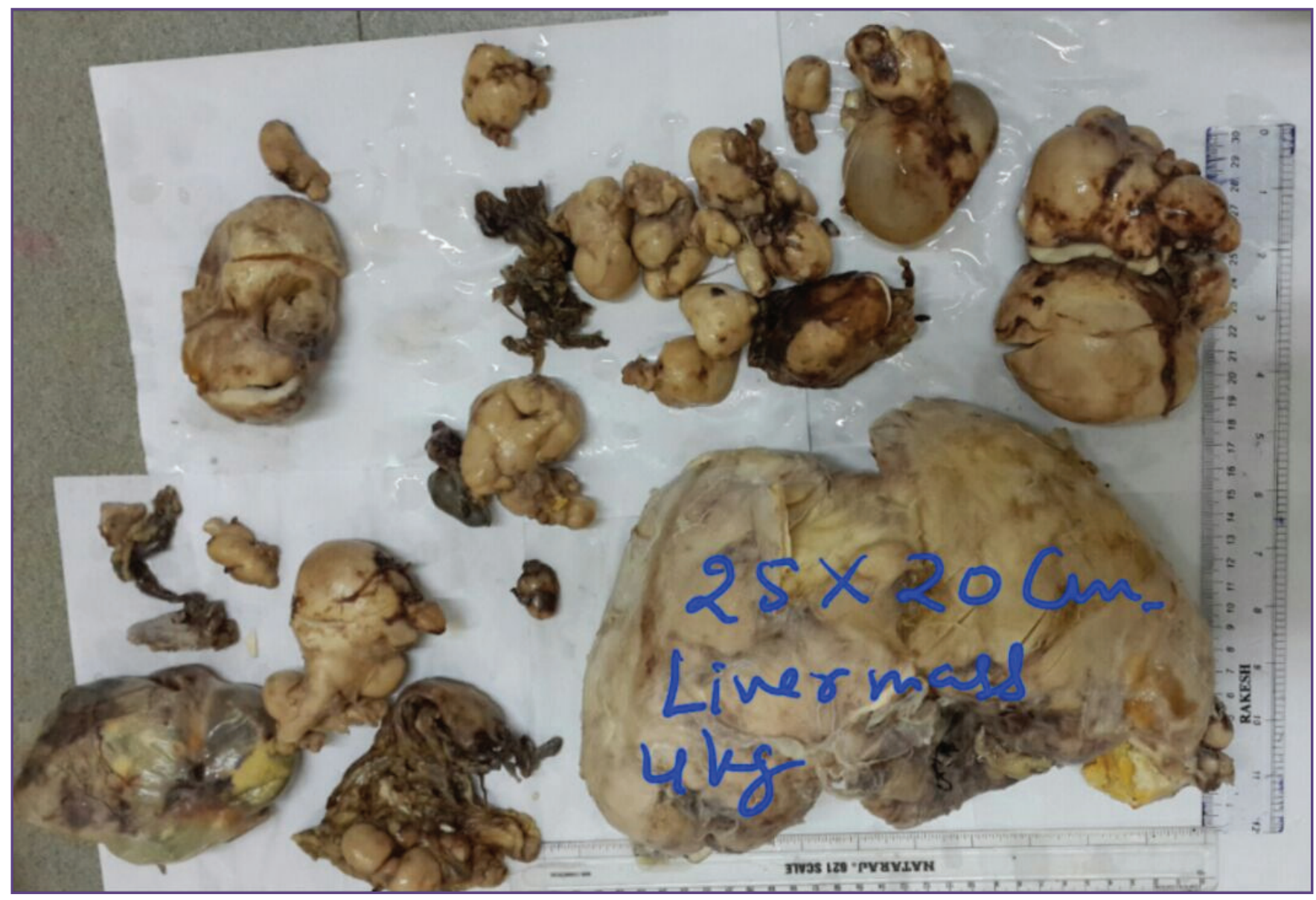

Fig. 2. Picture shows multiple tumor mass of variable sizes, largest from the liver measuring $25 \times 20 \mathrm{cms}$. 


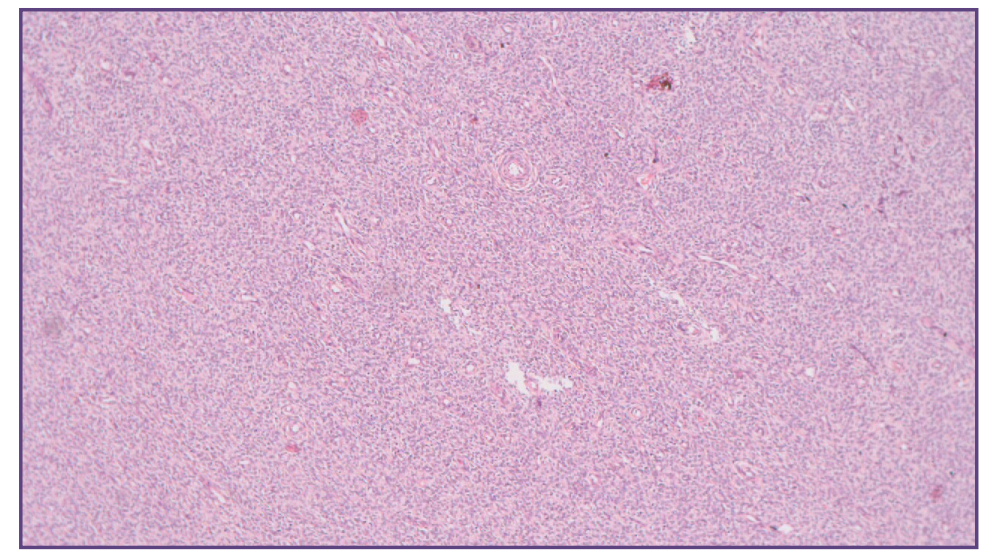

Fig. 3. Photomicrograph shows tumor cells predominantly arranged in sheets.

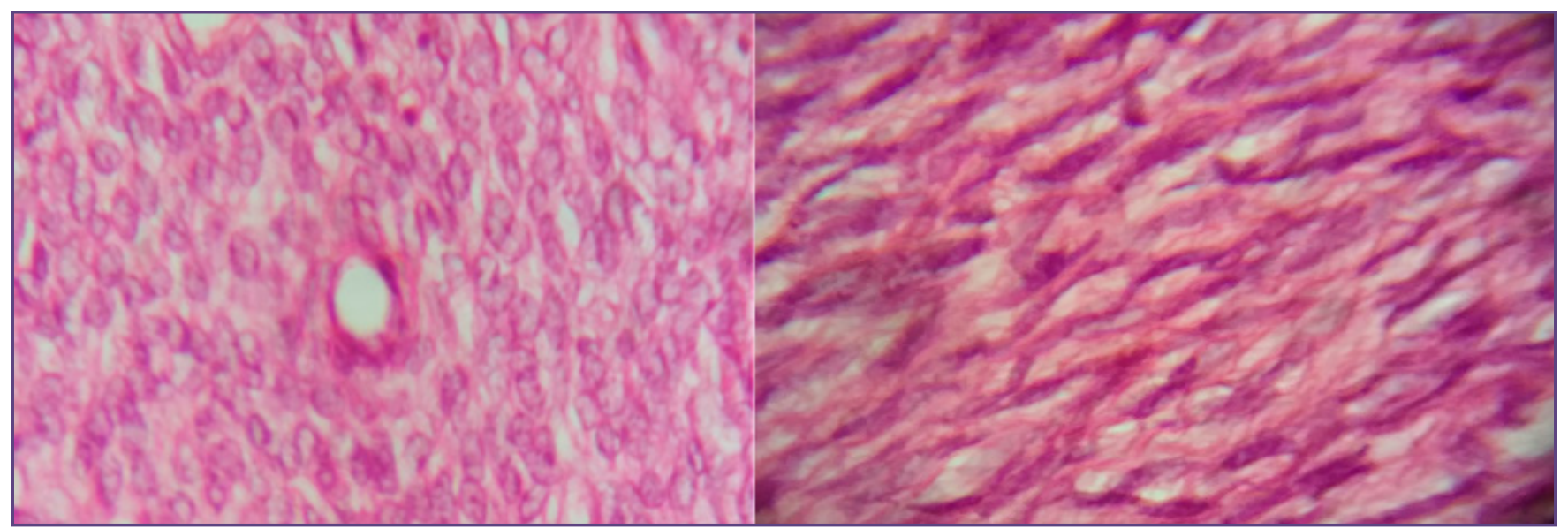

Fig. 4 photomicrograph shows epithelioid and spindle diffrentiation of the tumor cells.

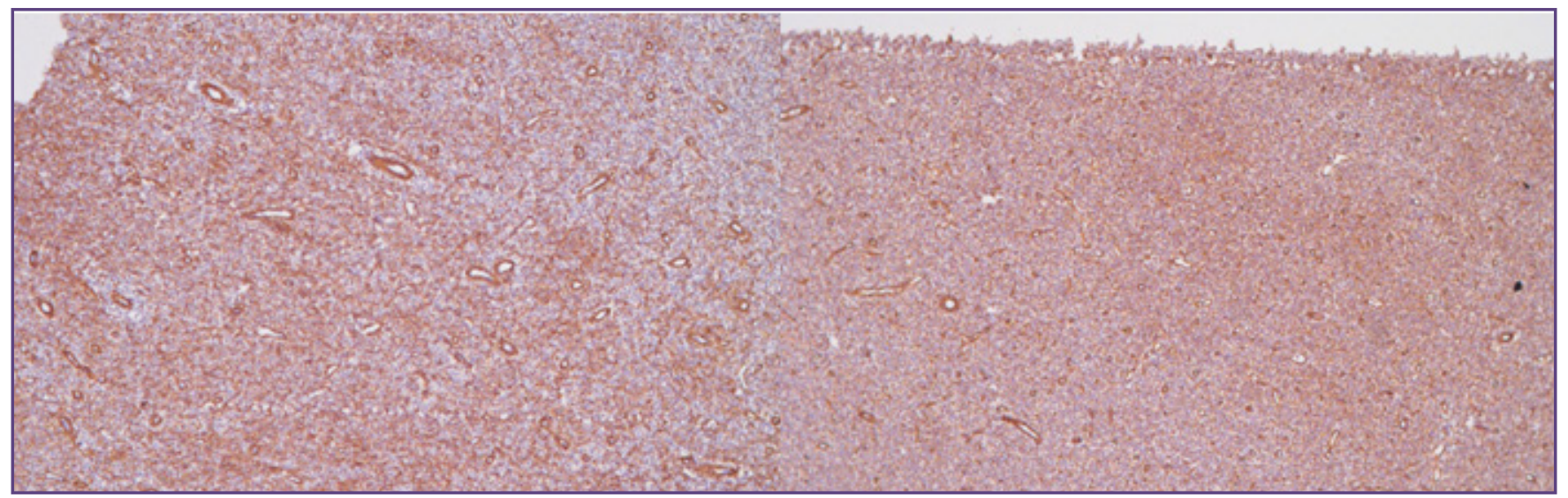

Fig. 5 photomicrograph showing vimentin and smooth muscle actin positivity respectively

occurs in middle-aged or older persons, although it may develop in young adults and even in children. The cause of soft tissue leiomyosarcoma is unknown. The predominant occurrence of retroperitoneal and inferior vena cava leiomyosarcomas in women raises the question of hormonal influence, but this is unclear. ${ }^{[5]}$
Leiomyosarcoma of soft tissue typically forms a fleshy mass, with colours varying from grey to white to tan. A whorled character may be evident to some degree. Larger examples often display haemorrhage, necrosis, or cystic change. Leiomyosarcoma of somatic soft tissue has a number of histological subtypes including epithelioid 
leiomyosarcoma, myxoid leiomyosarcoma, inflammatory leiomyosarcoma, granular cell leiomyosarcoma and dedifferentiated leiomyosarcoma.

Many case reports are published with multifocal leiomyosarcoma, most had primary in the GI tract. Roth and Carter et al and Friedie et al reported multicentric GI and extraGI leimyosarcomatosis in their case reports. ${ }^{[6,7]}$ Friedie et al reported a polypoidal smooth muscle tumor in patients GI tract and extensive extra intestinal smooth muscle tumors in the patients liver, lungs, parathyroid gland, bone marrow of the vertebrae and visceral organs including diaphragm, which on histomorphology was diagnosed as leiomyosarcoma.$^{[7]}$ On histology the differentiation of leiomyosarcoma includes - GIST , fibrosarcoma and malignant schwannoma. All these differentials are best differentiated on the basis of IHC panels. ${ }^{[8]}$ SMA and desmin are the specific markers for the diagnosis of the leiomyosarcomas. ${ }^{9}$ Raised CA125 in leiomyosarcoma is seen in uterine leiomyosarcoma. ${ }^{[10]}$ Vellanki et al reported a case of pelvic mass with raised CA125, which on histology was diagnosed as uterine leiomyosarcoma. ${ }^{[1]}$

Local control of soft tissue sarcomas is usually achieved with surgical resection. Pre operative planning based upon radiographic and pathologic information is important to ensure adequate surgical margins. Achieving wide surgical margins is important in preventing local recurrence. ${ }^{[12]}$ Radiation therapy is an important additional treatment for improving rates of local control when surgical margins are close, especially in high-grade sarcomas. Chemotherapy is employed for the treatment of the systemic diseases.These tumors display very aggressive biology. Neither size nor mitotic activity correlated with outcome, which may represent a reflection of the fact that most of these tumors are quite large on presentation. Local recurrences and metastases of soft tissue leiomyosarcoma usually become manifest within the first few years after diagnosis but may appear as much as 10 years later.

For retroperitoneal leiomyosarcomas, the most common sites of metastases are the lungs and liver, whereas the lungs are the dominant location when the primary tumour is nonretroperitoneal. Metastases also occur with some frequency in skin, soft tissue, and bone. Overall reported survival for patients diagnosed with soft tissue leiomyosarcoma range from $50 \% 3$-year survival to $64 \% 5$-year survival, making this tumor one of the more aggressive soft tissue sarcomas. ${ }^{[13]}$

\section{References}

1. Horvai A. Bones, Joints and Soft Tissue Tumors. In: Kumar V, Abbas, AK, Aster JC, editors. Pathological Basis of Disease. 9 Edition. Philadelphia: Elsevier; 2015: 1179-226.

2. Weaver MJ, Abraham JA. Leiomyosarcoma of the Bone and Soft Tissue: A Review. ESUN.2007;4:2.

3. Basic info". www.leiomyosarcoma.info. LMS leiomyosarcoma

4. Golden T, Stout AP. Smooth muscle tumors of the gastrointestinal tract and retroperitoneal tissues. Surg Gynecol Obstet.1941;73:784.

5. Evans HL., Shipley J. Leimyosarcoma. In: Christopher D.M. Fletcher, K. Krishnan Unni, Fredrik Mertens, editors. World Health Organization Classification of Tumours, Pathology and Genetics of Tumours of Soft Tissue and Bone. Lyon: 2002. 131-34.

6. Fridie IL, Hong IS, Green WR. Multicentric gastrointestinal and extraintestinal leiomyosarcomatosis: a case report. J Natl Med Assoc. 1992;84:7.

7. Roth JA, Carter H, Costabile DAn unusual multifocal leiomyosarcoma of the stomach: a light and electron microscopic study. Hum Pathol.1978;9:3.

8. Rodriguez FJ, Folpe AL, Giannini C, Perry A Pathology of peripheral nerve sheath tumors: diagnostic overview and update on selected diagnostic problems. Acta Neuropathol. 2012;123:3.

9. Schurch W, Skalli O, Seemayer TA, Gabbiani G. Intermediate filament proteins and actin isoforms as markers for soft tissue tumor differentiation and origin. I. Smooth muscle tumors. Am J Pathol. 1987;128.

10. Juang CM, Yen MS, Horng HC, Twu NF, Yu HC, Hsu WL. Potential role of preoperative serum CA125 for the differential diagnosis between uterine leiomyoma and uterine leiomyosarcoma. Eur J Gynaecol Oncol. 2006;27:4:370.

11. Vellanki VS, Rao M, Sunkavalli CB, Chinamotu RN, Kaja $\mathrm{S}$. A rare case of uterine leiomyosarcoma: a case report. J Med Case Rep. 2010;4:222.

12. Kandel R, Coakley N, Werier J, Engel J, Ghert M, Verma S. Surgical margins and handling of soft-tissue sarcoma in extremities: a clinical practice guideline. Curr Oncol. 2013;20:3.

13. Mankin, HJ, Casas-Ganem, J, Kim, JI, et al. Leiomyosarcoma of somatic soft tissues. Clin Orthop Relat Res. 2004;421.

*Corresponding author:

Dr. manika khare, Jaipur National University, Institute Of Medical Sciences And Research Centre, Jaipur, India

Email: drmanika09@gmail.com

Date of Submission : 27.12.2016

Date of Acceptance : 13.05.2017

Financial or other Competing Interests: None.

Date of Publication : 25.08.2017 